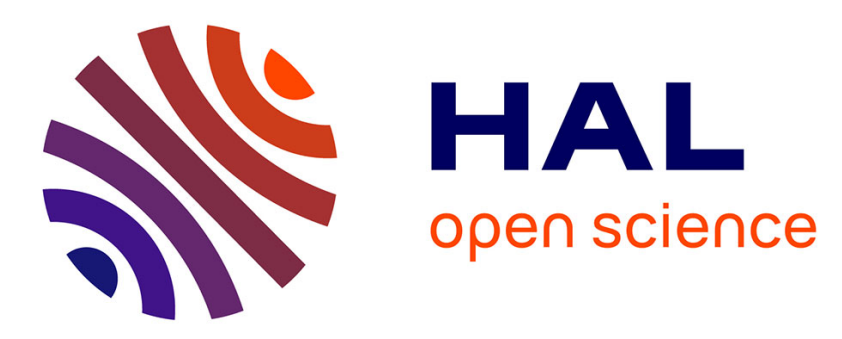

\title{
First profiling in hydrophilic interaction liquid chromatography of intact human chorionic gonadotropin isoforms
}

Julien Camperi, Valérie Pichon, Thierry Fournier, Nathalie Delaunay

\section{- To cite this version:}

Julien Camperi, Valérie Pichon, Thierry Fournier, Nathalie Delaunay. First profiling in hydrophilic interaction liquid chromatography of intact human chorionic gonadotropin isoforms. Journal of Pharmaceutical and Biomedical Analysis, 2019, 174, pp.495-499. 10.1016/j.jpba.2019.06.014 . hal-02329827

\section{HAL Id: hal-02329827 \\ https://hal.science/hal-02329827}

Submitted on 23 Oct 2019

HAL is a multi-disciplinary open access archive for the deposit and dissemination of scientific research documents, whether they are published or not. The documents may come from teaching and research institutions in France or abroad, or from public or private research centers.
L'archive ouverte pluridisciplinaire HAL, est destinée au dépôt et à la diffusion de documents scientifiques de niveau recherche, publiés ou non, émanant des établissements d'enseignement et de recherche français ou étrangers, des laboratoires publics ou privés. 
1 First profiling in hydrophilic interaction liquid chromatography of

\section{2 intact human chorionic gonadotropin isoforms}

3

4 Julien Camperi , Valerie Pichon ${ }^{a}{ }^{a}$, Thierry Fournier ${ }^{c}$, Nathalie Delaunay ${ }^{a}$

5

6 Laboratory of Analytical, Bioanalytical Sciences and Miniaturization, UMR CBI 8231 ESPCI

7 Paris, PSL University, Paris, France

8 Sorbonne Université, Paris, France

9 Laboratory of Physiopathology and PharmacoToxicology of the Human Placenta, UMR-S

101139 Inserm - University Paris Descartes, Sorbonne Paris Cité, Paris, France

12 Corresponding author: Nathalie Delaunay, nathalie.delaunay@espci.fr; +331 40794651.

Corresponding author institution: LSABM, UMR CBI 8231 CNRS - ESPCI Paris, 10 rue 


\section{Abstract}

The study of glycoproteins is a rapidly growing field, which is not surprising considering that approximately $70 \%$ of human proteins are glycosylated and that numerous biological functions are associated to the glycosylation. In this work, our interest focused on the heterodimeric human Chorionic Gonadotropin (hCG) glycoprotein that is the specific hormone of the human pregnancy, consisting of an $\alpha$ and a $\beta$ subunit, so-called hCG $\alpha$ and $\mathrm{hCG} \beta$, respectively. This protein possesses a very high structural heterogeneity, essentially due to the presence of 8 glycosylation sites, but also other types of post-translational modifications. In this study, for the first time, the potential of hydrophilic interaction liquid chromatography (HILIC) was investigated to separate the intact hCG isoforms. Three different HILIC stationary phases were tested using an hCG-based drug as standard, a recombinant hCG. For each stationary phase, the effect of the initial mobile phase composition based on $\mathrm{ACN} / \mathrm{H}_{2} \mathrm{O}$ mixture, the slope of the gradient, the content and nature of the acidic additive (formic acid and trifluoroacetic acid (TFA)), and the addition of a volatile salt (ammonium formate) on the retention and the resolution were studied. The best HILIC separation was obtained with the amide column and a mobile phase composed of water/ACN containing $0.1 \%$ of TFA. The repeatability in terms of retention times and peak areas was then assessed. Finally, the method was applied to the analysis of a second hCGbased drug obtained from urine of pregnant women. Both drugs gave chromatograms with more than 10 peaks. However, they were significantly different, which demonstrated the potential of HILIC method for hCG isoform fingerprinting.

Keywords: Glycosylation; HILIC chromatography; Human Chorionic Gonadotropin; Intact protein; Isoforms 


\section{Introduction}

41

Human Chorionic Gonadotropin (hCG) constitutes the first hormonal message from the placenta to the mother, detectable in maternal blood as early as one week after fecundation, and used in pregnancy diagnosis [1]. This protein is essential for the development of both placenta and fetus [2]. It is composed of two non-covalently linked subunits, hCG $\alpha$ and hCG $\beta$. The $\alpha$-subunit has a molecular weight (MW) of about 10,198 Da regardless of glycans and $2 \mathrm{~N}$-glycosylation sites and is common to the pituitary gonadotropin hormones such as the follicle-stimulating hormone, the thyroid-stimulating hormone, and the luteinizing hormone $[3,4]$. The $\beta$-subunit represents the specific part of hCG and has a MW of 15,521 Da regardless of glycans and $2 \mathrm{~N}$ - and 4 O-glycosylation sites [5]. Therefore, with 8 glycosylation sites, hCG is a highly heterogeneous protein.

Its characterization was already performed by analysing the glycopeptides obtained after an enzymatic digestion [6-8] or the released N-glycans after a PNGase-F treatment to obtain the glycan profiles of hCG-based drugs [5]. Furthermore, one study also demonstrated the potential of pronase to determine the composition of O-glycans present on the $\beta$-subunit [9]. However, all these approaches are time-consuming, because they require numerous pre-treatment steps, and they do not give the exact combinations of multiple posttranslational modifications (PTMs) of a given isoform. This is why today the fast and cheap analysis of intact glycoprotein presents a large interest.

High-performance liquid chromatography (HPLC) in combination with UV or mass spectrometry (MS) detection is now a common approach for the analysis of intact proteins $[10,11]$. Recently, we demonstrated the potential of reversed phase liquid chromatography (RPLC) for the separation of intact hCG isoforms [12]. However, RPLC may lack of selectivity to separate the hCG glycoforms whereas some papers dealing with other proteins showed 
that it could be performed by hydrophilic interaction liquid chromatography (HILIC) [13-17]. Indeed, HILIC allowed the monitoring of the glycosylation reaction with different glycans of a model protein (ribonuclease A) and 2 antigenic proteins hyphenated with UV or MS detection [13-15]. Periat et al. also demonstrated the potential of HILIC-UV for the quality control of therapeutic monoclonal antibodies [16]. Recently, Domínguez-Vega et al. demonstrated that HILIC associated to high-resolution MS allowed the profiling of interferon-beta-1a and the identification of 12 glycoforms [17]. They characterized also recombinant human erythropoietin (4 glycosylation sites) and they identified 51 glycoforms and other PTMs [17].

Here, for the first time, HILIC was investigated to separate the intact hCG isoforms. The chromatographic performances of three HILIC-columns (Accucore Amide, Mixed-Mode HILIC-1, and GlycanPac AXH-1) were compared. The effect of different parameters on the separation (initial mobile phase composition, slope of the gradient, temperature of analysis, injection volume, nature and content of salt) were studied for each column. Finally, the best column with the optimal conditions was used for the analysis of 2 hCG-based drugs demonstrating the potential of HILIC for hCG isoform fingerprinting.

\section{Materials and methods}

\subsection{Reagents and analytes}

HPLC-grade acetonitrile (ACN) and formic acid (FA) were supplied by Carlo Erba (Val de Reuil, France). Ammonium formate (AF) and trifluoroacetic acid (TFA) were purchased from SigmaAldrich (Saint Quentin Fallavier, France). The ultra-pure water was obtained with a Direct-Q3 UV system (Millipore, Molsheim, France). Ovitrelle ${ }^{\circledR}$ (Serono Europe Ltd., London, UK) and 
Pregnyl ${ }^{\circledR}$ (Organon, Oss, The Netherlands), are drugs based on recombinant hCG ( $\mathrm{r}$-hCG) and urinary hCG (u-hCG), respectively. Ovitrelle ${ }^{\circledR}$ was available as a solution containing $250 \mu \mathrm{g}$ of $\mathrm{r}-\mathrm{hCG}$, and Pregnyl as a lyophilized powder containing $5000 \mathrm{IU}$ u-hCG (1 IU is equivalent to a concentration of $\left.0.092 \mu \mathrm{g} \mathrm{L}{ }^{-1}[18,19]\right)$.

The Ovitrelle ${ }^{\circledR}$ solution was reconstituted in $0.5 \mathrm{~mL}$ of water to obtain a stock solution containing $500 \mu \mathrm{g} \mathrm{mL}^{-1}$ of $\mathrm{r}$-hCG. For Pregny ${ }^{\circledR}$, the lyophilized content of each ampoule was dissolved in $1 \mathrm{ml}$ of water to obtain a concentration of $460 \mu \mathrm{g} \mathrm{mL}^{-1}$. All the preparations were aliquoted and stored at $-20^{\circ} \mathrm{C}$. Before injection, the hCG fractions were washed and pre-concentrated at $1 \mathrm{mg} \mathrm{mL}^{-1}$ by centrifugation with ultra-centrifugal units (Merck, Darmstadt, Germany) having a molecular weight cut-off of $10 \mathrm{kDa}$.

\subsection{Instrumentations and columns}

The experiments were carried out with a 1260 Infinity instrument (bio-inert system), equipped with a quaternary pump, an autosampler, a column oven, and a UV detector (Agilent Technologies, Les Ulis, France). The three studied HILIC-columns were: Accucore Amide (150 x 2.1 mm, $2.6 \mu \mathrm{m}, 150 \AA$ Å), Acclaim Mixed-Mode HILIC-1 (150 x $2.1 \mathrm{~mm}, 3 \mu \mathrm{m}$, $120 \AA ̊$ ), and GlycanPac AXH-1 (150 x 2.1 mm, $3 \mu \mathrm{m}, 120 \AA$ A ), all purchased from ThermoFisher (Le Pecq, France). The injection volume was fixed at $1 \mu \mathrm{L}$ and the flow rate at $0.4 \mathrm{~mL} \mathrm{~min}^{-1}$. The column temperature was fixed at $50^{\circ} \mathrm{C}$ for the Acclaim Mixed-Mode HILIC-1 column, and at $60^{\circ} \mathrm{C}$ for the two other columns. FA, TFA, and AF were tested in different proportions in mobile phases composed of acetonitrile and water. Gradient elution conditions were optimized for each HILIC column. The detection was performed at $214 \mathrm{~nm}$. 


\section{Results and discussions}

111

112

113

114

115

116

117

118

119

120

121

122

123

124

125

126

127

\subsection{Preliminary choices of the mobile and stationary phases}

First, we selected different HILIC stationary phases. Only ones with large particle pore sizes ( $\geq 120 \AA$ ) were considered to avoid exclusion of the isoforms from the pores. The most commonly used stationary phase for HILIC analysis of intact proteins in literature is amidebonded silica, which demonstrated a good potential for the protein glycoprofiling [13-17]. Therefore, an Accucore amide stationary phase with core-shell particles was selected. The mixed-mode GlycanPac AXH-1 column was also selected, since it was developed for the separation of uncharged and charged N-glycans combining weak anion exchange and HILIC mechanisms, although its performance has not been evaluated yet for the separation of intact proteins. Finally, an Acclaim Mixed-Mode HILIC-1 column based on silica bonded with an alkyl chain with a diol end group, used mainly for the separation of surfactants [20], was also selected, although no application to proteins has been reported yet. Therefore, these three stationary phases are expected to provide quite different retention mechanisms for the hCG isoforms.

First experiments were achieved with $\mathrm{r}$-hCG used as standard, as it was expected to be the purest of our two available hCG-based drugs. A mobile phase containing a water/ACN mixture acidified with $0.1 \%(\mathrm{v} / \mathrm{v})$ TFA was used, since its strong influence on retention in HILIC was reported [21]. Indeed, TFA acts as an ion-pairing agent and it generates some solvating effect that both impact selectivity, retention, resolution, and peak shape [22]. Even if Periat et al. demonstrated that the temperature does not have a significant impact on the HILIC separation as on RPLC [16], values between 50 and $65^{\circ} \mathrm{C}$ were used in HILIC for the separation of intact glycoproteins [13-17]. Therefore, the column temperature was fixed at 
$60^{\circ} \mathrm{C}$ for the Accucore Amide and GlycanPac AXH-1 columns and at $50^{\circ} \mathrm{C}$ for the Acclaim Mixed-Mode HILIC-1 column, which corresponds to the maximal recommended temperature given by the manufacturer.

\subsection{Injection conditions}

The biggest challenge in HILIC for the analysis of intact proteins is the injection conditions, i.e. to have sample media that do not induce a significant deformation of chromatographic peaks while allowing the solubilization of the protein without causing its precipitation. Indeed, the dissolution in a solvent with a high ACN content (e.g. 70-90\%) close to the mobile phase composition cannot be done with proteins, since they precipitate [23]. Therefore, samples were prepared by dissolving hCG in water containing different ACN contents $(10,20$, and $30 \%)$. and by injecting a reduced volume $(1 \mu \mathrm{l}$, about $0.2 \%$ for the sample-to-column volume ratio) to prevent from the peak deformation induced by the high percentage of water [24]. It was observed that the chromatographic performances in terms of efficiencies and retention times did not change (data not shown), confirming the results of Ruta et al. [24]. Therefore, hCG was dissolved only in water for the rest of the study, thus ensuring a better stability of hCG samples.

\subsection{Optimization of the gradient for each column}

Different initial ACN contents (between 85 and 65\%) and slopes of the mobile phase gradient (from $4.5 \%$ down to $0.25 \%$ per $\mathrm{min}$ ) were tested with each HILIC column. Figure 1 presents the resulting chromatograms obtained with the conditions leading to the best separation for each column. 

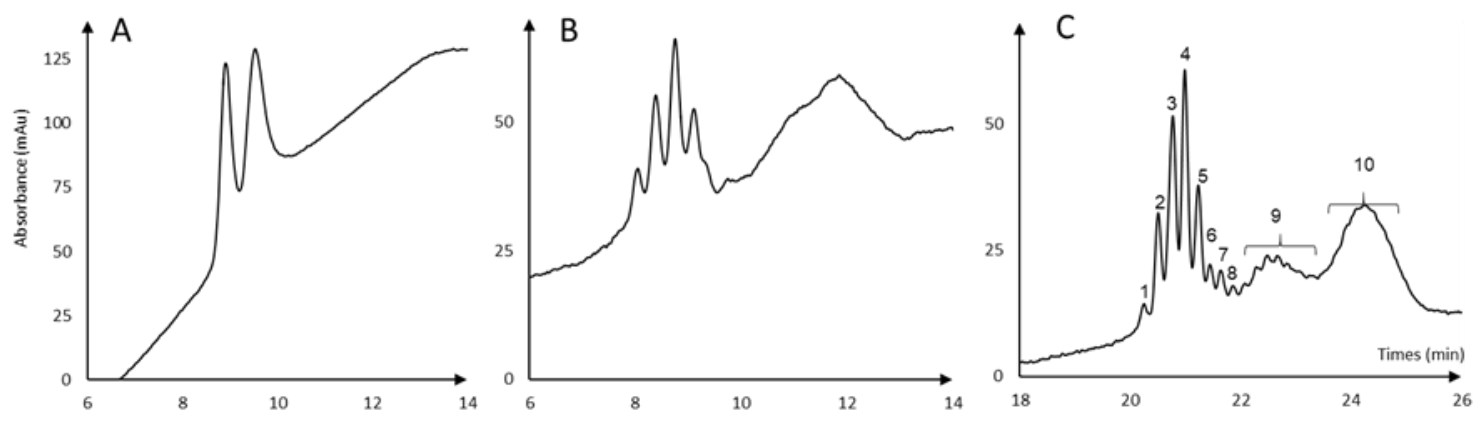

Figure 1: Analysis by HILIC of r-hCG with the three tested columns and the most appropriate mobile phase gradient for each. Mobile phase: $0.1 \%$ TFA in $\mathrm{H}_{2} \mathrm{O} / \mathrm{ACN}$ mixture (v/v). (A) Acclaim Mixed-Mode HILIC-1; Gradient: $90 \%$ ACN for $3 \mathrm{~min}$, from 90 to $60 \% \mathrm{ACN}$ with a slope of $4.5 \% \mathrm{~min}^{-1}$, (B) GlycanPac AXH-1; Gradient: from 85 to $40 \%$ of $A C N$ with a slope of $1.5 \% / \mathrm{min}$ and, (C) Accucore Amide; Gradient: from 85 to $40 \%$ of $A C N$ with a slope of $1.5 \% \mathrm{~min}^{-1}$. r-hCG: $1 \mathrm{mg} \mathrm{mL}^{-1}$ in water. Other conditions: see experimental section.

With the Acclaim Mixed-Mode HILIC-1 column, the best separation was achieved by applying an isocratic elution at $90 \%$ ACN for 3 min followed by a gradient from 90 to $60 \%$ with a slope of $4.5 \% \mathrm{~min}^{-1}$ (Figure $1 \mathrm{~A}$ ). Only two peaks at 8.8 and $9.6 \mathrm{~min}$ were observed in these conditions. With the GlycanPac AXH-1 column (Figure 1B), a mobile phase gradient from 85 to $40 \%(1.5 \%$ per $\mathrm{min})$ gave a better separation than the first column within two distinct elution zones. Indeed, at least 4 peaks were observed between 7.8 and 9.6 min and a second large one between 10.1 and 12.9 min but with an insufficient resolution to distinguish peaks. The best HILIC separation was obtained with the amide-bonded stationary phase (Figure 1C) as already observed in the literature for other glycoproteins. Using the same mobile phase gradient as for the GlycanPac AXH-1 column, the separation enabled to distinguish three elution zones: $19.8-21.8 \mathrm{~min}, 21.8-23.4 \mathrm{~min}$, and $23.4-25.2 \mathrm{~min}$. For the first zone, 8 peaks were observed. For the second and the third zones, the presence of several peaks can also be suspected, but the resolution is still insufficient here. Nevertheless, this stationary phase 
seems to be the most appropriate to separate a very large number of hCG isoforms and demonstrates the high heterogeneity of this protein. Moreover, the number of peaks obtained here by the analysis of intact hCG isoforms in HILIC is significantly superior to the one obtained in RPLC [12]. At this stage, it is possible to assume that each peak may correspond to at least one isoform, including glycoform or other PTMs. However, the UV detection does not allow going further in the characterization of hCG isoforms.

\subsection{Test of different additives in the mobile phase}

The replacement of $0.1 \%$ TFA by $0.1 \%$ of FA in the mobile phase was considered. Unfortunately, the separation of isoforms dramatically dropped for the three HILIC-columns. Indeed, as shown in Figure $2 \mathrm{~A}$ that presents a chromatogram obtained using the amidebonded stationary phase, only one large zone of co-eluting peaks was obtained. For the two other columns, a single large peak was observed (see Figures S1A and S1B in the supplementary data). Then, different percentages of FA, from $0.1 \%$ to $1 \%$, were tested but no improvement of the resolution was observed.

Other ionic additives, such as ammonium acetate or ammonium formate, are commonly used in HILIC because they can reduce the proteins adsorption and modify the solvation property, affecting the separation mechanism [25]. Therefore, different concentrations of AF $(10,50$, and $100 \mathrm{mM})$ in the mobile phase were tested. The $\mathrm{pH}$ was adjusted in the aqueous part at 2.2 with FA. With the Acclaim Mixed-Mode HILIC-1 column, no peak was observed whatever the AF concentration (see Figure S1C). The best separation was obtained with 100 mM AF for the GlycanPac AXH-1 and the Accucore amide columns (Figures S1D and 2B, respectively), but in both cases only 4 peaks were observed. Therefore, the chromatographic performances were largely inferior to the ones with $0.1 \%$ of TFA in mobile phase, which 

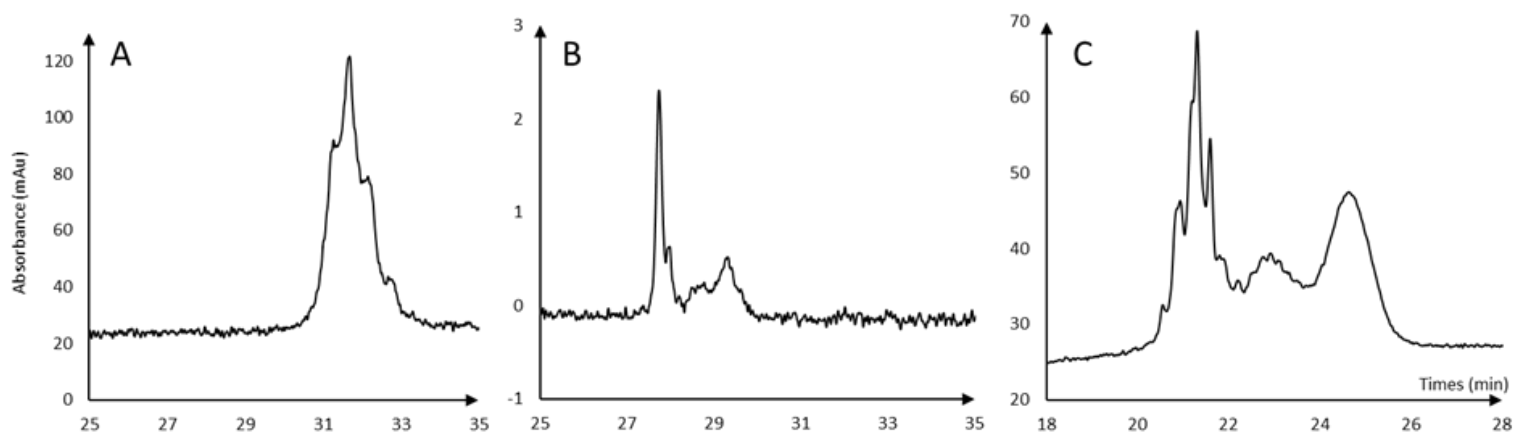

Figure 2: Effect of different additives in the mobile phase on the HILIC analysis of r-hCG. Mobile phase: $\mathrm{H}_{2} \mathrm{O} / \mathrm{ACN}$ mixture $(\mathrm{pH}$ 2.2) plus (A) $0.1 \% \mathrm{FA}$, (B) $1 \% \mathrm{FA}+100 \mathrm{mM} A F$, and (C) $0.05 \%$ TFA.

Column: Accucore Amide. Gradient: from 85 to $40 \%$ of ACN with a slope of $1.5 \% \mathrm{~min}^{-1}$. r-hCG: $1 \mathrm{mg}$ $\mathrm{mL}^{-1}$ in water. Other conditions: see experimental section.
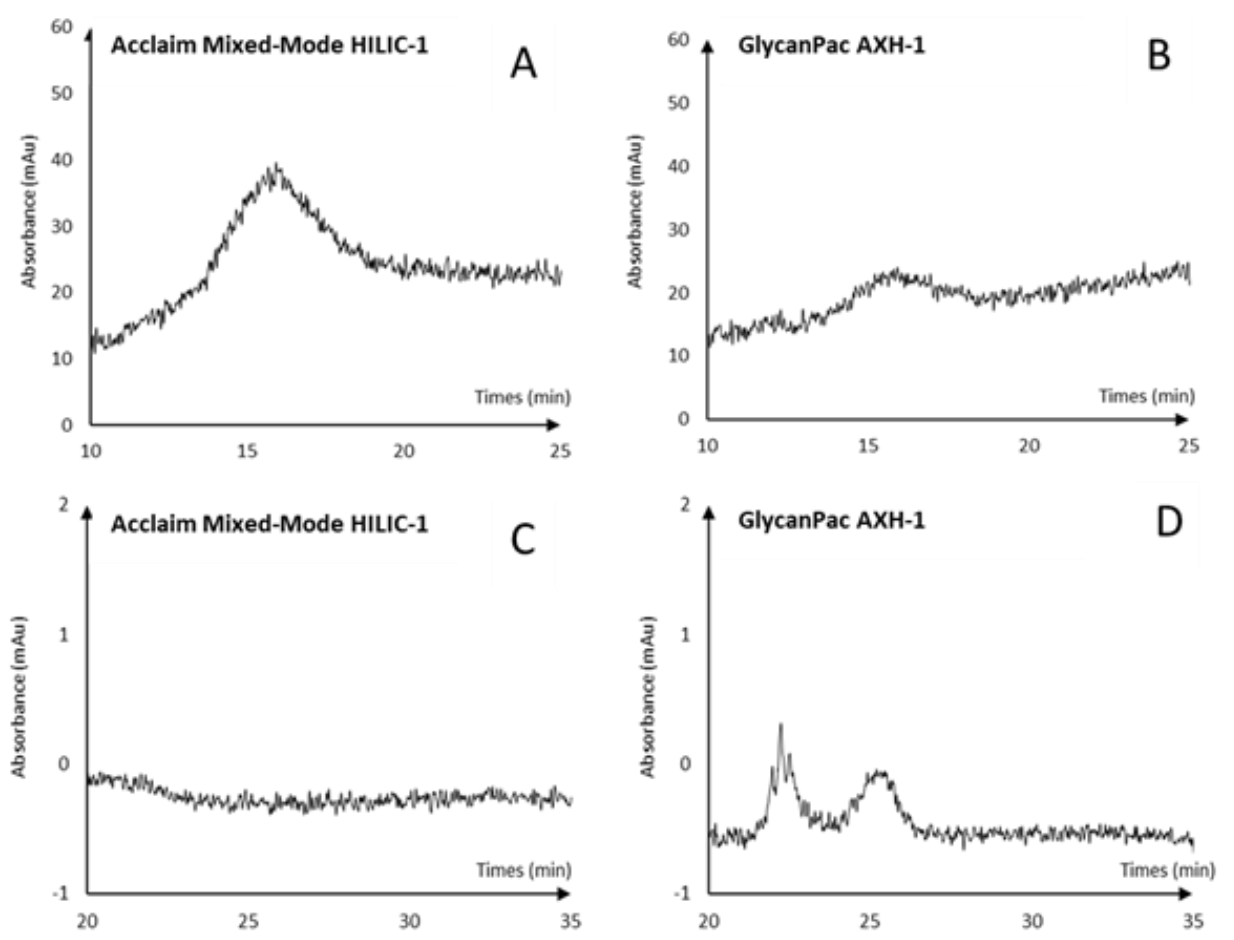

Figure S1: Effect of different additives in the mobile phase on the HILIC analysis of $r$-hCG. (A, B) $0.1 \%$ of FA and (C,D) $100 \mathrm{mM} \mathrm{AF}+1 \%$ FA. (A, C) Acclaim Mixed-Mode HILIC-1. (B, D) GlycanPac AXH-1 columns. Gradient: from 85 to $40 \%$ of $\mathrm{ACN}$ with a slope of $1.5 \% \mathrm{~min}^{-1}$, Temperature, (A, C) $50^{\circ} \mathrm{C}$ and (B, D) $60^{\circ} \mathrm{C}$. r-hCG s: $1 \mathrm{mg} \mathrm{mL}^{-1}$ in water. Other conditions: see experimental section 
Finally, as the presence of TFA appears as mandatory in the mobile phase, its percentage

215 was reduced to $0.05 \%$. If we compare the resulting chromatogram (Figure $2 \mathrm{C}$ ) to the one obtained with $0.1 \%$ of TFA (Figure $1 \mathrm{C}$ ), both are similar but with a decrease in resolution when the TFA content decreases ( 5 vs 8 peaks were observed for the first elution zone). The last parameter tested to improve again the separation was a decrease in the flow-rate but no significant improvement of resolution values was obtained (between 0.91 and 1.10) whereas the analysis time increased dramatically.

To conclude, the Accucore Amide column with a mobile phase composed of water and ACN containing $0.1 \%$ TFA gave the most efficient separation of hCG isoforms. The resolution values of the peaks of the first elution zone (between 19.8 and $21.8 \mathrm{~min}$ ) were calculated and they are between 0.81 and 1.02 (see Table 1). The repeatability was then assessed. As shown in Table 1, the relative standard deviation (RSD) values for the retention times was inferior to $0.84 \%$, which demonstrate the repeatability of this analytical method. The RSD values for peak areas between 2.5 and $12.3 \%$ may demonstrate some instability of the sample.

Table 1: Resolution and RSD values of the retention times and the areas of the peaks obtained by the HILIC analysis of r-hCG with the optimized conditions ( $n=3)$. r-hCG: $1 \mathrm{mg} \mathrm{mL}^{-1}$ in water. For peak number: see Figure 3.

\begin{tabular}{|c|c|c|c|c|c|c|c|c|c|c|}
\hline Peak number & 1 & 2 & 3 & 4 & 5 & 6 & 7 & 8 & 9 & 10 \\
\hline$\%$ RSD tr (\%) & 0.84 & 0.70 & 0.57 & 0.64 & 0.66 & 0.56 & 0.43 & 0.84 & 0.55 & 0.62 \\
\hline$\%$ RSD Area (\%) & 12.28 & 5.40 & 3.52 & 2.52 & 4.80 & 5.23 & 7.54 & 8.05 & 10.23 & 12.25 \\
\hline Resolution & - & & & & & & & & - & - \\
\hline
\end{tabular}




\subsection{Analysis of 2 hCG-based drugs}

Once the separation parameters were optimized with r-hCG, a second hCG-based drug obtained from urine of pregnant women (u-hCG) was analyzed using the same conditions. As for $\mathrm{r}$-hCG, Table 2 presents the RSD values of the retention times of the main peaks of $u-h C G$ and they were between 0.25 and $1.92 \%$. The RSD values for the peak areas were between 3.6 and $14.3 \%$. Chromatograms of u-hCG (Figure 3A) and r-hCG (Figure 3B) are significantly different. With $\mathrm{u}$-hCG, the separation profile reveals a first elution zone with at least 10 peaks between 18.7 and $21.6 \mathrm{~min}$, partially resolved $(0.67<\mathrm{Rs}<0.99$, see Table 2$)$, and a second with one large peak between 23.1 and 25.5 min. Unfortunately, the separation conditions do not allow the separation of isoforms present in this second zone.

Table 2: Resolution and RSD values of the retention times and the areas of the peaks obtained from the HILIC analysis of $\mathrm{u}$-hCG with the optimized conditions ( $\mathrm{n}=3)$. u-hCG: $1 \mathrm{mg} \mathrm{mL}^{-1}$ in water. For peak number: see Figure 3.

$\begin{array}{lllllllllll}\text { Peak number } & 1^{\prime} & 2^{\prime} & 3^{\prime} & 4^{\prime} & 5^{\prime} & 6^{\prime} & 7^{\prime} & 8^{\prime} & 9^{\prime} & 1^{\prime}\end{array}$

\begin{tabular}{l|c|c|c|c|c|c|c|c|c|c}
\hline \% RSD tr (\%) & 0.45 & 0.92 & 0.43 & 0.32 & 0.34 & 0.55 & 0.25 & 0.47 & 0.88 & 0.56 \\
& & & & &
\end{tabular}




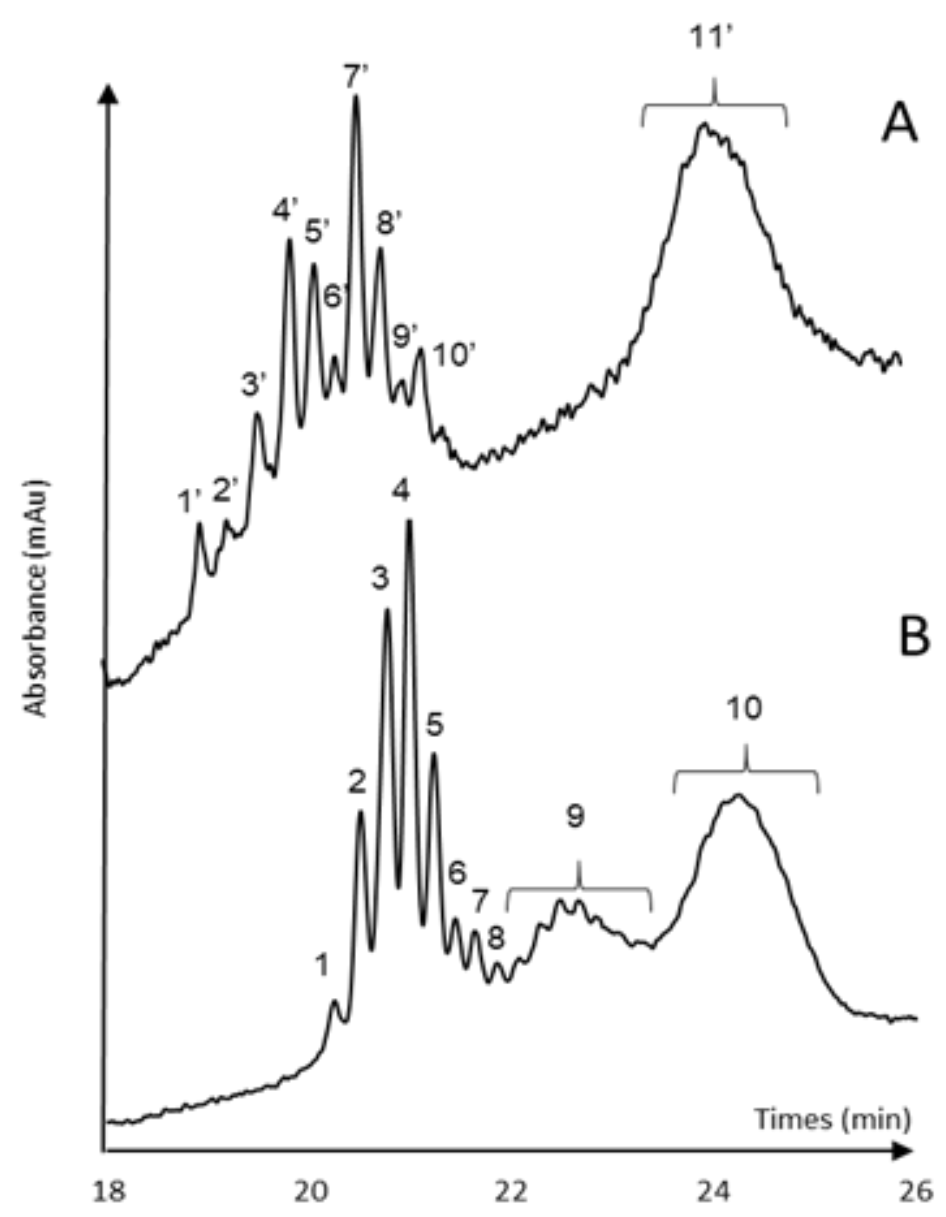

Figure 3: Superposition of the (A) u-hCG and (B) r-hCG HILIC chromatograms. Accucore Amide column. Mobile phase: $0.1 \%$ TFA in $\mathrm{H}_{2} \mathrm{O} / \mathrm{ACN}$ mixture (v/v). Gradient: from 85 to $40 \%$ of ACN with a slope of $1.5 \% \mathrm{~min}^{-1}$. r- and u-hCG: $1 \mathrm{mg} \mathrm{mL}^{-1}$ in water. Other conditions: see experimental section

Compared with r-hCG, the first and the second elution zones of u-hCG have about the same range of retention times than those obtained with $\mathrm{r}$-hCG for the first (19.8-21.8 $\mathrm{min})$ and the third (23.4-25.3 $\mathrm{min}$ ) elution zones. However, it is worthwhile to notice here that (i) the retention times for each peak within the first elution zone are different for both drugs, and that (ii) the second elution zone between 21.8 and 23.4 min present for r-hCG was not observed on the u-hCG chromatogram. Therefore, these results clearly revealed the 
presence of hCG isoforms that differ in number and nature in the two hCG-based drugs. This HILIC-UV method can therefore easily distinguish the two drugs, with a relatively short analysis time (26 $\mathrm{min}$ ) and reasonable cost, and could be used for quality control of hCGbased drugs or fingerprinting studies in real biological samples.

\section{Conclusions}

For the first time, the potential of HILIC was evaluated for the separation of the isoforms of the highly glycosylated hCG at the intact level. Despite the different analytical challenges of the HILIC mode for the analysis of intact protein such as injection conditions, it was demonstrated that the amide HILIC-column is able to resolve numerous hCG isoforms. Despite uncomplete resolution of this method, its potential for fingerprinting approach was demonstrated. If a higher level of information is necessary, such as the number of glycoforms, their composition, their structure, and the presence of other types of PTMs, the hyphenation with high resolution MS is mandatory. This constitutes the next step of this study.

\section{Acknowledgments}

This work has received the support of "Institut Pierre-Gilles de Gennes" (laboratoire d'excellence, "Investissements d'avenir" program ANR-10-IDEX-0001-02 PSL and ANR-10LABX-31). The authors also thank Mr. Claude Netter for the Acclaim Mixed-Mode HILIC-1 column. 


\section{References}

[1] T. Fournier, J. Guibourdenche, D. Evain-Brion, Review: hCGs: different sources of production, different glycoforms and functions, Placenta 36 (2015) S60-S65.

[2] J. Guibourdenche, L. Burc, J. Frendo, G. Flament, A. Kacprzak, I. Bazot, P. Jeanne, D. Porquet, F. Muller, Physiopathologie de l'hormone chorionique gonadotrope humaine (hCG) dans la trisomie 21 fœtale, Immuno-Anal. Biol. Spéc. 17 (2002) 2-10.

[3] M.J. Kessler, T. Mise, R.D. Ghai, O.P. Bahl, Structure and location of the O-glycosidic carbohydrate units of human chorionic gonadotropin, J. Biol. Chem. 254 (1979) 7909-7914.

[4] L. Liu, D. Leaman, M. Villalta, R.M. Roberts, Silencing of the gene for the alpha-subunit of human chorionic gonadotropin by the embryonic transcription factor Oct-3/4, Mol. Endocrinol.

[5] C. Liu, L.D. Bowers, Mass spectrometric characterization of the beta-subunit of human chorionic gonadotropin, J. Mass Spectrom. 32 (1997) 33-42.

[6] R.D. Nerenz, A.W. Butch, G.A. Woldemariam, M.L. Yarbrough, D.G. Grenache, A.M. Gronowski, Estimating the hCG $\beta c f$ in urine during pregnancy, Clin. Biochem. 49 (2016) 282-286.

[7] H. Lund, E. Paus, P. Berger, U.-H. Stenman, T. Torcellini, T.G. Halvorsen, L. Reubsaet, Epitope

[8] H. Lund, K. Løvsletten, E. Paus, T.G. Halvorsen, L. Reubsaet, Immuno-MS based targeted proteomics: highly specific, sensitive, and reproducible human chorionic gonadotropin determination for clinical diagnostics and doping analysis, Anal. Chem. 84 (2012) 7926-7932.

[9] M. Wuhrer, A.R. de Boer, A.M. Deelder, Structural glycomics using hydrophilic interaction chromatography (HILIC) with mass spectrometry, Mass Spectrom. Rev. 28 (2009) 192-206. 
[10] S. Fekete, D. Guillarme, P. Sandra, K. Sandra, Chromatographic, Electrophoretic, and Mass Spectrometric Methods for the Analytical Characterization of Protein Biopharmaceuticals, Anal. Chem. 88 (2016) 480-507.

[11] K. Sandra, I. Vandenheede, P. Sandra, Modern chromatographic and mass spectrometric techniques for protein biopharmaceutical characterization, J. Chromatogr. A. 1335 (2014) 81103.

[12] J. Camperi, A. Combes, J. Guibourdenche, D. Guillarme, V. Pichon, T. Fournier, N. Delaunay, An attempt to characterize the human Chorionic Gonadotropin protein by reversed phase liquid chromatography coupled with high-resolution mass spectrometry at the intact level, J. Pharm. Biomed. Anal. 161 (2018) 35-44.

[13] A. Pedrali, S. Tengattini, G. Marrubini, T. Bavaro, P. Hemström, G. Massolini, M. Terreni, C. Temporini, Characterization of Intact Neo-Glycoproteins by Hydrophilic Interaction Liquid Chromatography, Molecules 19 (2014) 9070-9088.

[14] F. Rinaldi, S. Tengattini, E. Calleri, T. Bavaro, L. Piubelli, L. Pollegioni, G. Massolini, C. Temporini, Application of a rapid HILIC-UV method for synthesis optimization and stability studies of immunogenic neo -glycoconjugates, J. Pharm. Biomed. Anal. 144 (2017) 252-262.

[15] S. Tengattini, E. Domínguez-Vega, C. Temporini, T. Bavaro, F. Rinaldi, L. Piubelli, L. Pollegioni, G. Massolini, G.W. Somsen, Hydrophilic interaction liquid chromatography-mass spectrometry as a new tool for the characterization of intact semi-synthetic glycoproteins, Anal. Chim. Acta. 981 (2017) 94-105.

[16] A. Periat, S. Fekete, A. Cusumano, J.-L. Veuthey, A. Beck, M. Lauber, D. Guillarme, Potential of hydrophilic interaction chromatography for the analytical characterization of protein biopharmaceuticals, J. Chromatogr. A. 1448 (2016) 81-92.

[17] E. Domínguez-Vega, S. Tengattini, C. Peintner, J. van Angeren, C. Temporini, R. Haselberg, G. Massolini, G.W. Somsen, High-resolution glycoform profiling of intact therapeutic proteins by hydrophilic interaction chromatography-mass spectrometry, Talanta 184 (2018) 375-381. 
[18] P. Berger, A.J. Lapthorn, The molecular relationship between antigenic domains and epitopes on hCG, Mol. Immunol. 76 (2016) 134-145.

[19] P. Berger, C. Sturgeon, J.M. Bidart, E. Paus, R. Gerth, M. Niang, A. Bristow, S. Birken, U.H. Stenman, Towards user-oriented standardization of pregnancy and tumor diagnosis: assignment of epitopes to the three-dimensional structure of diagnostically and commercially relevant monoclonal antibodies directed against human chorionic gonadotropin and derivatives, Tumour Biol. 23 (2002) 1-38.

[20] X. Liu, C.A. Pohl, J. Weiss, New polar-embedded stationary phase for surfactant analysis, J. Chromatogr. A. 1118 (2006) 29-34.

[21] S. Fekete, D. Guillarme, Ultra-high-performance liquid chromatography for the characterization of therapeutic proteins, TrAC Trends Anal. Chem. 63 (2014) 76-84.

[22] Z. Zhang, Z. Wu, M.J. Wirth, Polyacrylamide brush layer for hydrophilic interaction liquid chromatography of intact glycoproteins, J. Chromatogr. A. 1301 (2013) 156-161.

[23] A. Astefanei, I. Dapic, M. Camenzuli, Different Stationary Phase Selectivities and Morphologies for Intact Protein Separations, Chromatographia 80 (2017) 665-687.

[24] J. Ruta, S. Rudaz, D.V. McCalley, J.-L. Veuthey, D. Guillarme, A systematic investigation of the effect of sample diluent on peak shape in hydrophilic interaction liquid chromatography, J. Chromatogr. A. 1217 (2010) 8230-8240.

[25] B. Buszewski, S. Noga, Hydrophilic interaction liquid chromatography (HILIC)-a powerful separation technique, Anal. Bioanal. Chem. 402 (2012) 231-247. 